\title{
TORCH: An instructional model from FS praxis
}

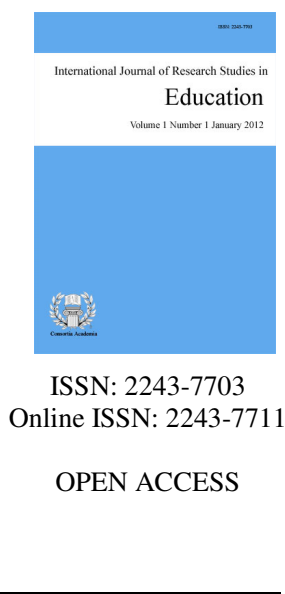

Montebon, Darryl Roy T. $\triangle$

Philippine Normal University, Philippines (montebon.drt@pnu.edu.ph)

Calamlam, Josephine M.

Philippine Normal University, Philippines (calamlam.jm@pnu.edu.ph)

Varela, Leonora P.

Philippine Normal University, Philippines (varela.lp@yahoo.com)

\section{Abstract}

Field study courses provide significant experiences for pre-service teachers to prepare them to take on the challenges of performing the different roles of a teacher. In the university where the present research is conducted, the field experiences are included in the course Practice Teaching 1 which is made up of field study courses to meet the requirements of the teacher education curriculum in the Philippines. The present research is an attempt to innovate an instructional model that is seen to assist the supervising instructors of the different teacher education institution in the Philippines. The designed instructional model is anchored on the different activities implemented by the experts in supervising the field study courses at the university where the present research is conducted. The designed instructional model has an acronym TORCH that stands for the different stages at which the instruction would proceed.

Keywords: TORCH for field study; field experiences instructional model; field study; Philippines; research methodology 


\section{TORCH: An instructional model from FS praxis}

\section{Introduction}

Metaphorically, the process of preparing teachers in the teacher education program is analogous to the process of preparing a torch that can be used to light a dark place. Compared with the torch, the materials that comprise it are much the same as the courses pre-service teachers are taking in their respective courses. These courses should provide pre-service teachers with a strong foundation of concepts, theories, and strategies that pre-service teachers can utilize in lighting the dark classroom where students that need guidance await. The fuel that will enable teachers to produce light are their personal beliefs, skills, and passion for teaching. But what will ignite the fire that will make the torch aflame? The answer is in the quality of exposure of pre-service teachers to understand real classroom teaching and learning through field studies and practice teaching. Hence, the focus of present research is on field experiences.

As teacher educators, the researchers believe that the Philippine Normal University (PNU) is performing its function in producing teachers who will carry the torch and light their destined academes. Through the different field study courses, the pre-service teachers are trained to confront the different challenges that they will face in the classroom through their field study courses. The field study is an important phase with which pre-service teachers should undergo for them to be exposed to the realities of the learning environment (Arnett \& Freeburg, 2008). The experiences in the field study allow pre-service teachers to realize the different aspects of the teaching and learning process. Though pre-service teachers are relatively passive in the field study compared with the practice teaching programs, it allows them to process their insights from their observations and eventually enables them to discern if teaching is the career they want to pursue (Hoy \& Woodfolk, 1990).

The PNU Institute of Teaching and Learning offers the field study courses where pre-service teachers are exposed to the teaching and learning environment. In the field study courses, pre-service teachers are also gradually being introduced to practice teaching. Though the field study courses have been implemented by the Institute of Teaching and Learning (ITL) of PNU since 2004, some dilemma on its implementation still exist. The supervising instructors have no standard mode of teaching the different field study courses. Thus, variability in pre-service teachers' experiences in their field studies has been observed. Hence, the researchers designed an instructional model to address the said concern. At present, a considerable turnover of teachers in the ITL has occurred because most of the senior teachers have been assigned to the different faculties of the university. Such phenomenon poses a threat on the quality of instruction that can be offered in the field study courses. Therefore, the designed instructional model is seen to assure quality instruction in the field study courses.

Understanding the present situation, a research gap has been identified in terms of research on field study in the Philippines. Most researches that were reviewed for this study focused on assessing the implementation of the field study courses but not on how it is being taught in the universities. Thus, it is imperative for an instructional model to be used to facilitate learning in the field study courses to maximize the field experiences of the pre-service teachers.

\section{Review of Related Literature}

\subsection{Field Study Experience}

In a teacher-education program, the relationship between theory and practice is most essential. According to the National Research Council (2010) of the USA, the value of structured and systematic field experience among pre-service teacher is the most critical stage of a teacher-education program. Teachers acknowledge that the courses they had in universities do not necessarily match with the challenges they encountered in the realms of 
teaching and learning. Thus, field experiences among pre-service teachers are important because it initially prepares them to connect theory and practice (Arnett \& Freeburry, 2008). Field experiences are essential in developing a holistic teacher. These field experiences are offered in the Field Study (FS) courses. FS courses provide pre-service teachers with an entire range of school experiences, structured observations, course related experiences, and student teaching. Field experiences serves as the framework for developing the passion for teaching and the grit to perform the roles of a teacher.

How is FS different from the teaching practicum? The FS courses are not as rigid as the teaching practicum phase because in FS, pre-service teachers are primarily observers of the teaching and learning practice. Therefore, the degree of involvement of a pre-service teacher taking FS is less compared with that of the practicum teacher. The pre-service teachers taking FS courses are not expected to assume teaching responsibilities but are required to observe, assist, and participate in certain activities (Arnet \& Freeburg, 2008). The FS courses and the teaching practicum are important stages pre-service teachers should pass through. Adding the FS course in the curriculum of teacher education provides more exposure to the teaching realm among pre-service teachers and it is very helpful to them (Pickard, 2004). It means that the more time the pre-service teacher spends in the classroom, the higher is their confidence level in taking on the challenges of being a teacher and it increases their teaching efficacy as well. Through the field experiences and increased time in the classroom, pre-service teachers are able to clarify their beliefs about teaching (Arnett \& Freeburg, 2008). The process providing pre-service teachers with early teaching experiences contributes to the articulation of their purpose, pedagogical content knowledge, and understanding of the behavior of learners (Liston \& Zeicher, 1991).

In a related study, the need to re-imagine how courses are conceptualized and connected has been raised. FS courses are seen to address this need where pre-service teachers learning is shared and imbedded in authentic contexts of teaching and learning (Sanford, Hopper, \& Starr, 2015). Observing teachers in authentic context help pre-service teachers reflect, shape, and reapply their understanding.

\subsection{Field Study in Philippine Context}

The Commission on Higher Education (CHED) in the Philippines acknowledges that the quality pre-service teacher education program is a key factor in improving the quality education in the country (CMO 30, 2004). Quality education in the country primarily lies on the type of teacher being produced by the Teacher Education Institutions (TEI). Thus, teacher education curriculum should be given of primary importance. The teacher education curriculum in the Philippines envisions to produce a holistic teacher equipped with pedagogical content knowledge that they can utilize in performing the different roles of a teacher. Therefore, it is imperative that standards should be established for the profession. In response, the Philippine Normal University as the National Center for Teacher Education in the country encourages researches on how to improve and nurture teacher education curriculum is highly encouraged. Hence, the present research aims to help in the described agenda.

The teacher education curriculum offers different courses for general education, specialization and content and professional education. The field study and the practice teaching is under the professional education course. In all, for a pre-service teacher to obtain a diploma in education, he or she must complete about 175 units mixed of university coursework, practicum, and research. The Field Study (FS) courses are composed of 6 courses (FS 1 to 6) with 1 unit each course. Each field study course concentrates on a certain topic that investigates the different dynamics in the classroom. Table 1 below shows the course title and description for each FS course.

The pre-service teachers take the field study courses during their third in the university. For other TEI's, field study is conducted in their partner public schools. In PNU, the FS courses are being handled by the professors in the Institute of Teaching and Learning which serves as the university's laboratory school. At present, the PNU is undergoing a curriculum change and the 6 field study courses are combined in one course named Practice Teaching 1 (PT 1). 
Montebon, D. R. T., Calamlam, J. M., \& Varela, L. P.

Table 1

Descriptions of Field Study Courses (Experiential Courses Handbook, 2009)

\begin{tabular}{|c|c|c|}
\hline Course Code & Course Title & Course Objectives \\
\hline Field Study 1 & $\begin{array}{l}\text { The Learner and the Learning } \\
\text { Environment }\end{array}$ & $\begin{array}{l}\text { Verify the behavior of the child in the actual learning } \\
\text { environment } \\
\text { Recognize feasible approaches to facilitate learning }\end{array}$ \\
\hline Field Study 2 & Facilitating Learning & $\begin{array}{l}\text { Examine the application of teaching theories and } \\
\text { principles in the learning environment } \\
\text { Verify cognitive, metacognitive, individual differences, } \\
\text { and motivational factors that influence the acquisition of } \\
\text { knowledge } \\
\text { Develop and try out learning tasks, instructional materials, } \\
\text { and assessment tools }\end{array}$ \\
\hline Field Study 3 & The Curriculum & $\begin{array}{l}\text { Apply and verify knowledge gained on curriculum } \\
\text { development through exposure to the existing curriculum }\end{array}$ \\
\hline Field Study 4 & Preparing Instructional Materials & $\begin{array}{l}\text { Enrich students experience in developing and utilizing } \\
\text { appropriate technology to facilitate learning }\end{array}$ \\
\hline Field Study 5 & Assessment of Learning & $\begin{array}{l}\text { Experience the selection, construction, and evaluation of } \\
\text { authentic and alternative assessment tools in the learning } \\
\text { environment based on the principles of testing }\end{array}$ \\
\hline Field Study 6 & On Becoming a Teacher & $\begin{array}{l}\text { Reflect on the different preparations of becoming teacher } \\
\text { through real life and vicarious experiences }\end{array}$ \\
\hline
\end{tabular}

Patan (2010) evaluated the implementation of the FS courses in their region and found out several academic and procedural problems. Though most respondents agreed that they are implementing the FS course to best of their abilities, challenges still arise. Some of the problems identified in the study of Patan (2010) are similar with the challenges that PNU ITL is facing which are:

$>\quad$ The amount of requirements against the time to complete them

$>\quad$ The time for FS courses compete with their time for university coursework

$>$ Conflict between the resource teachers and FS pre-service teachers

$>\quad$ Lack of quality time for mentoring

However, the result of the work of Dela Rosa (2014) disagrees with that of Patan (2010). Upon the assessment of Dela Rosa (2014) in how they have conducted the FS program in their university, she found out that pre-service teachers and FS resource teachers perceived the program to be highly successful because it allows them to connect theory with practice, which is the very aim of the FS courses. Time has not been an issues in the implementation of the course as well. The disagreement in the study of Patan (2010) and (Dela Rosa, 2014) may have been due to the time that the research was conducted and the locality of the researches.

The studies available about the FS courses in the Philippines is more focused on the implementation of the program and not on how it can be better implemented. Research was found to be limited in terms of describing any innovation in the FS programs. Thus, such lack of research in the said area can be described as gap. Hence, the present research aims to address in minimizing the said gap.

\subsection{The research questions}

The aim of this research is to design an instructional that can be utilized by university supervisors of the field study courses. The experiences of supervisors who were able to facilitate different FS courses are relevant to the desired instructional model. To attain such goal, the researcher sought to investigate on the following questions.

What are the FS strategies employed by the supervising instructors handling FS courses?

$>\quad$ What are the challenges encountered by the supervising instructors in handling the FS courses? 
$>\quad$ What instructional model can be designed that would provide optimum and parallel experiences to all pre-service teachers in their FS course?

\section{Methodology}

The research context and respondents - The respondents of this research are the 12 professors (supervising instructors), 4 male and 8 female, who have experienced supervising field study courses. Their length of experience ranges from 3 to 10 to yrs. This qualitative research employs the interview and focused group discussion procedures to answer the research questions. The responses were coded and classified in a pre-identified theme discussed in the related literature. Common practices were identified and suggestions were noted.

\section{Results}

\section{Q1. What are the FS strategies employed by the college supervisors handling FS courses?}

To begin each FS course, the respondents unanimously agreed that they are conducting orientation program for their students. Orientation procedures can be done individually or with collaboration with other FS supervisors. The orientation process primarily introduces the FS students to the FS courses, the course outline, and the requirements for each FS course. The expectations of the FS students were also being discussed during the orientation program.

To assess students' prior knowledge for each FS course, the institute provided a checklist on the different aspect of teaching and learning. According to Respondent 2, the checklist serves as the pre-assessment on what pre-service teachers know, what they want to know, and how supervisors can help them learn the knowledge and develop the skills on teaching and learning. In the class of Respondent 1 , she made her students submit sample work (e.g lesson plan, modules, \& assessment materials) from their professional education. She then conducts small group session to critique the sample materials submitted.

To proceed with each FS course, the FS supervisors have described different activities. Such activities were reported in the succeeding paragraphs:

$>\quad$ To optimize pre-service teachers experiences in each field study courses, the PSTS went through observation phase which enables them to affirm the theories they learned in their university coursework, determine methods that work in the classroom, and correct misconceptions on how the teaching and learning process occur. To do this, the FS supervisors shared common activities like making pre-service teachers accomplish a guided observation checklist. In FS 1, students are tasked to go back to the school where they had their secondary or elementary education in the activity called Balik Alma Mater. For FS 2, the pre-service teachers were able to observe how their FS supervisors facilitate the class through a classroom demonstration. In the class of Respondent 4, he videotaped the performance of each group in the classroom demonstration and allowed the class to critique it.

$>\quad$ For FS 3 which is on curriculum, the pre-service teachers where assigned to study the respected $\mathrm{K}$ to 12 curriculum and conduct classroom observations to see its implementation in the classroom. Respondent 2 described that in his class, the pre-service teachers conducted interviews with the teachers and different school personnel how the curriculum meets their school's vision, mission, goals, and objectives (VMGO).

$>\quad$ For FS 4, which is on the Instructional Manual, the pre-service teachers focused their observations on the instructional materials in the classroom and the ones utilized by the teachers in facilitating learning. Bulletin boards found in the different parts of the school were also considered for observation. 
$>$ FS 5 focuses on the assessment of student learning. In this course, pre-service teachers were exposed to the different formative and summative assessments. All respondents made their FS students to analyze a sample traditional and authentic assessment procedures. In the class of Respondent 6, pre-service teachers were allowed to accomplish the rubric for scoring a task in a home economics class and later on compared the scores to that of the teacher. In the class of Respondent 2, he made pre-service teachers to focus their observations on the behavior of students and write them in an anecdotal record.

$>$ FS 6 highlights on Becoming a Teacher, where pre-service teachers are made to observe the different characteristics of teachers and the ethics that they need to be demonstrate. The common activity for this course is a case study of either an excellent teacher or a problematic one. Moreover, while observing the teachers in the different FS courses, the students were tasked to list the different characteristic or dispositions of a teacher in either formal or informal situations. They should be able to describe how teachers project themselves in the classroom and in school, how they communicate with students and other people, and how they carry on other responsibilities of a teacher.

Reflection is an important skill that pre-service teachers should develop. The ability to reflect equates with the spirit of continuous improvement to enable a practitioner to be better in his or her practice.

In the present research, how the FS supervisors encouraged their pre-service teachers to be reflective in their practice was investigated. To do so, they were asked, "What reflective practices did you employ to make your FS students learn from the experiences you provided them?" The most common answer that was listed is through journal entries. For every activity, the pre-service teachers were asked to journal all the things they have learned from it. To direct pre-service teachers' entry to be on a professional level rather than personal, they were guided to write specifically on something that they have learned, how their pre-conceived knowledge differ from what they have experienced, and how their insights could help them when they will become teachers in the future.

Another activity that was a practice common on making pre-service teachers reflect is the pre and post conferencing procedures. Respondent 3 said that she conducts pre-conferencing activities to level off the pre-service teachers' expectation and the post conference is conducted to reflect on their observations and insights gained. All respondents agreed that a post conference after their class demonstration is very important for it allows pre-service teachers to reflect on their performance.

Other specific activities that were identified are reflection papers, curriculum analysis with emphasis on the difference as to how they were taught back in elementary and high school, and picture analysis of their performance in class.

The pre-service teachers were also assessed in each FS course and the most common activity for assessment that was utilized is the preparation of portfolio. Each pre-service teacher was assigned to submit a professional portfolio of what they have learned in their FS courses. The portfolio generally contains the checklists, the journal entries, the observations sheets, and other documents that are related to their FS courses.

"I usually make my pre-service teachers do a parallel activity done in pre-conference. They will compare the growth of their understanding about teaching and learning. Usually there is a repeat observation where they are involved in the planning and implementation" - Respondent 3

To let the pre-service teachers apply what they learned in their FS class is an important aspect that was considered by the supervising instructors of the course. Thus, different application activities have been utilized. Table 2 below enumerates the said activities. 
Table 2

Application Activities

\begin{tabular}{ll}
\hline \multicolumn{1}{c}{ FS Course } & \multicolumn{1}{c}{ Activity } \\
\hline 1 - The Learners and the Environment & Creation of an Ideal School Map \\
& Drafting of school's organizational chart \\
& Graphic Organizer of the nature of learners \\
& Analysis of the needs of the stakeholders \\
& Listing of the characteristics of today's learners \\
& Classroom demonstration \\
& Lesson Planning \\
& Teacher's toolkit \\
& A poster (traditional or electronic version) illustrating an \\
& academically engaged classroom \\
& Textbook critiquing as congruency with curriculum \\
& Comparative analysis of the Philippine curriculum and that of Asia \\
& Preparing Scope and sequence \\
& Preparing budget plantilla \\
& Helping in preparing instructional materials \\
& Bulletin board creation \\
& School brochure making \\
& Preparing Table of specification \\
& Test creation and piloting \\
& Test banking \\
& Item Analysis \\
& Visioning one's career path \\
& Case study \\
\hline
\end{tabular}

\section{Q2. What are the challenges encountered by the supervising instructors in handling the FS courses?}

The university supervisors agreed that the implementation of the FS courses is challenging both in terms of administration and implementation. The most common challenge on FS that was identified is the conflicting time between the FS course and the university coursework of students. Respondent 5 said that some of her pre-service teachers were not able to comply with the time required for each course because it is in conflict with their classes in the university.

To address the said problems, the ITL department conferred with the vice-president for academics and the university registrar to arrange the schedule. It has also been designed as such for FS courses to be taken by PST across two semesters rather than just one. The teaching load for each FS course was also settled to give due remuneration to the supervising instructors.

Another challenge identified was the number of pre-service teachers that each supervising instructor has to accommodate in his or her class. To address the said challenge, the supervising instructors divided the section into different groups to accommodate them in the class. A certain day for observation was assigned for each group and a class sharing of observations was done.

Respondent 2 said that at times he find it hard because "It is like re-teaching the concepts that they had in their Professional education courses" To address the concern, he gives a mini-lecture of the concepts that he wants his pre-service teachers to learn or observe in each FS course.

The researchers also asked the respondents on what they can suggest to further improve the FS experiences offered by the institute. The respondents offered the suggestions are listed below.

$>$ Observations should be in two phases, one in ITL and the other one in public schools

$>$ FS students should be allowed to witness the final demo of the practice teachers in off campus 
$>$ Instructional plan required in the FS course should be parallel with the format used in public schools

$>$ A program or conference could be organized for practice teachers to share their experiences with the FS pre-service teachers.

> Instructional materials should go beyond preparation of bulletin board but should be more of showing research innovations

$>$ A seminar on proper grooming or teacher decorum should be conducted

Q3. What instructional model can be designed that would provide optimum and parallel experiences to all pre-service teachers in their FS course?

Based on the responses from research questions 1 and 2, an instructional model for implementing ITL's Practice Teaching 1 course, has been constructed to include all field study courses. The instructional model was developed from the emerging themes from the described experiences of the practice teachers. Figure 1 below shows the instructional model which carries the acronym TORCH.

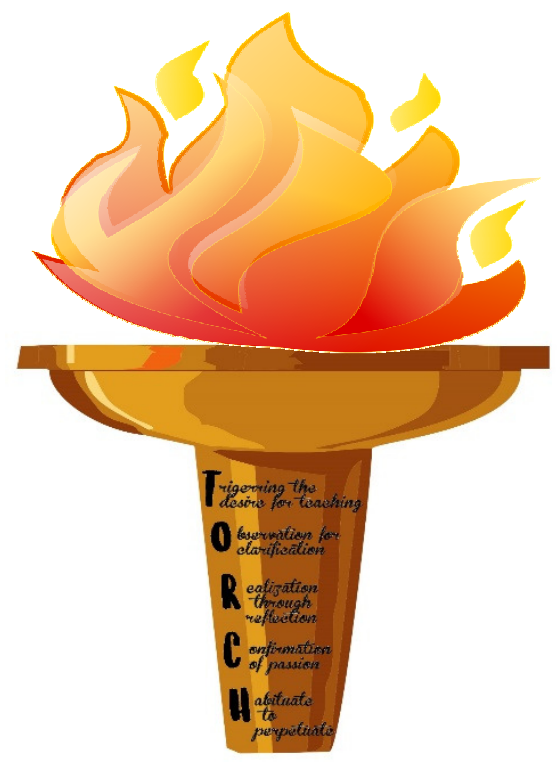

Figure 1. The TORCH Instructional Model

Triggering the desire for teaching - The 'triggering' stage is an important phase that signals the beginning of the intense training that pre-service teachers has to go through as they embrace the teaching vocation. Field experience sparks their ultimate decision and commitment to pursue a career in teaching and to inspire professional development in the field (Bruckerhoff \& Carlson, 1995). Field experiences allow pre-service teachers to articulate their purpose (Liston \& Zeichner, 1991).

The respondents of the present research acknowledge the importance of getting the attention of the pre-service teachers to determine if teaching is something that they really want to pursue. The different activities to orient the PSTS give chance to the supervising instructors to pre-assess the skills of the pre-service teachers and determine their own philosophy of teaching.

Observation for clarification - Pre-service teachers have prior conceptions on how the teaching and learning process occur in the classroom (Eisenhardt, Besnoy, \& Steele, 2012). Such beliefs and opinions are being affirmed by the field study experiences. Through the guided observations in the field study, the pre-service teachers can identify, confront, and challenge prior conceptions on the process of teaching and learning. 
The result of the present research agrees with what the supervising instructors have experienced in the observation phase of the field study. The different modes observations that were utilized by the supervising instructors were geared towards letting them see the realities of the teaching and learning process. In the observation phase, the pre-service teachers were able to clarify their misconceptions on how the teaching and learning processes operate. Further, the observation phase is an opportunity for pre-service teachers to gather methods and strategies from the supervising instructors and other resource materials to improve their craft.

Realization through reflection - The majority of the experiences of pre service teachers in the university coursework are more on the side of being a student rather than being a teacher (Arnett \& Freeburg, 2008). Therefore, field experience allows pre-service teacher to explore the role of being a teacher in the different activities that they perform. Field experience will promote realizations among the pre-service teachers that with the changing landscape of education, it is necessary that to realize the need for addressing the increasing diversity of learners. The pre-service teachers should be able to reflect on the teaching practices that may work or may not work among the students (Eisenhardt, Besnoy, \& Steele, 2012).

To determine the different realizations of pre-service teachers on the realms of teaching and learning, the supervising instructors studied the self and group reflections of their pre-service teachers through their journals and other activities. By reading pre-service teachers' reflections, the supervising instructors were able to understand the extent to which they have achieved their goals as mentors of the pre-service teachers. The process of reflection is an important metacognitive tasks for the pre-service teachers for them to maximize their full potential.

Confirmation of passion - To realize how to teach rather than what to teach can be accomplished through field experience (Hart and Teeter, 2002). Thus, a clearer understanding of the teaching realm can happen to the pre-service teacher during the field experiences (Arnett \& Freeburg, 2008). In case of dissonance, the field study experiences allow the pre-service teachers to check, negotiate, and alter their conflicting beliefs and experiences.

To confirm if students' observations and experiences are really what the supervising instructors would like to teach their pre-service teachers, feedbacks through conferences are given. During the post conference the pre-service teachers were asked to describe how they feel about their performances on the activities and the supervising instructors then confirm they have the same perceptions and observations. Through the conferences done, an exchange ideas flowed to confirm and reaffirm behaviors that are useful in performing the roles of a teacher in the classroom. Doing this, pre-service teachers are able to assess their performance thus, decreases the tendency of dissonance.

Habituate to perpetuate - To habituate in the preset research means to apply in practice what has been learned from the field experiences and thus perpetuate a system of teaching excellence. By then, it can be deduced that learning on teaching has been accomplished since transfer is one condition of learning once or a skill or a concept is acquired. The real test of learning is for pre-service teachers to apply them to another context. FS experiences provide insights that are transferrable to another context. Continuous practice shapes the pre-service teachers identity.

How the pre-service teachers can apply what they have learned from the different activities provided by the supervising instructors can is the most important aspect of the field experience. Through field study the pre-service teachers can start to assume certain roles of a teacher.

\section{Conclusion and Recommendation}

The present study shows that field study courses in ITL have been taught in different ways but with certain commonalities. Therefore, it is apt to have a unifying instructional method to enable pre-service teachers to have parallel experience to optimize their potentials. Hence, the instructional method called TORCH was designed. Figure 2 below shows how to proceed with the said instructional model. 


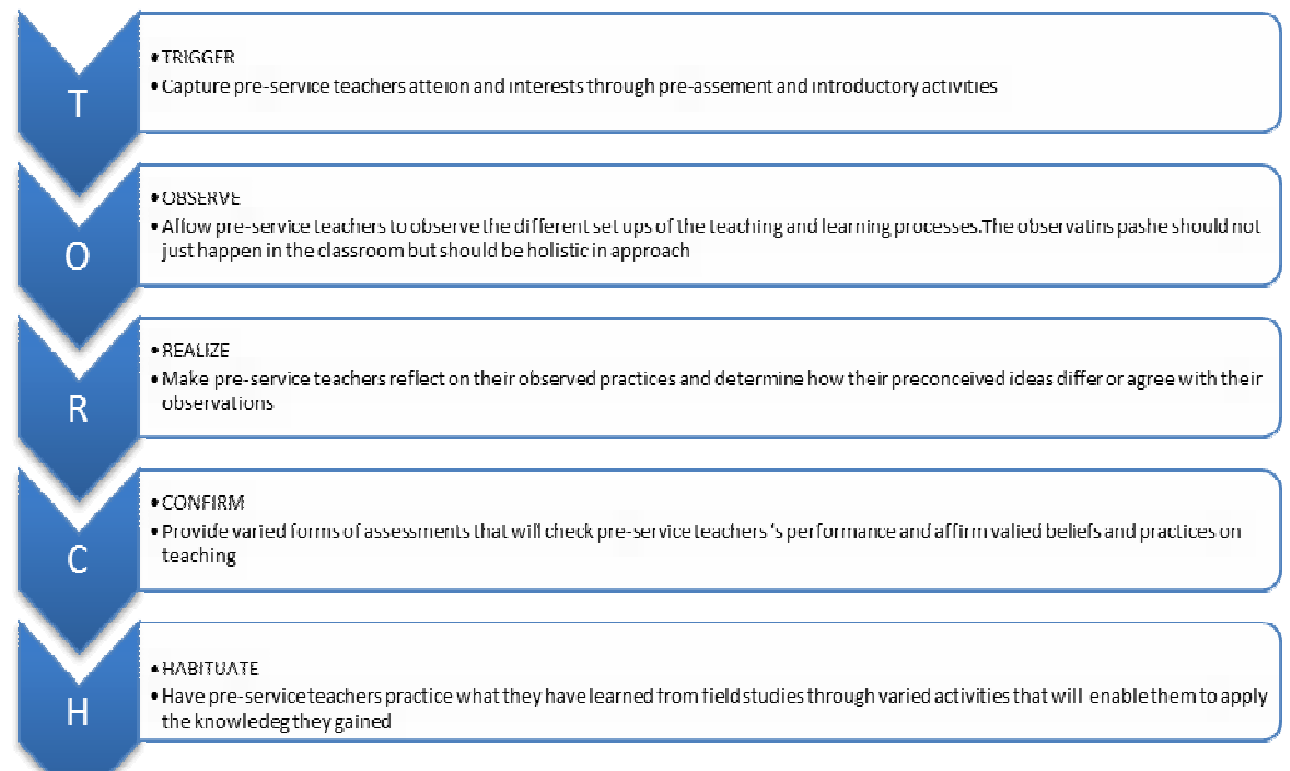

Figure 2. The Torch Model

For future research, it is recommended that the TORCH instructional model be implemented and determine if it has an effect on pre-service teachers' readiness towards teaching, teaching efficacy, and other related variables.

\section{References}

Arnett, S., \& Freeburg, B. (2008). Family and consumer sciences pre-service teachers: Impact of an early field experience. Journal of Family and Consumer Sciences Education, 26(1), 48-56.

CHED Memorandum Order No. 30. (2006). Retrieved from http://nlpdl.nlp.gov.ph:81/CH01/MO/2006/CH0MO0030s2006.pdf

Dela Rosa, S. (2014). The field study program of the college of education, University of Eastern Philippines: An Evaluation. International Journal of Humanities and Management Sciences, 2(3), 136-139.

Eisenhardt, S., Besnoy, K., \& Steele, E. (2012). Creating dissonance in pre-service teachers' field experiences`. Southeastern Regional Association of Teacher Educators, 21(1), 1-10.

Hart, P. D., \& Teeter, R. M. (2002). A national priority: Ameri cans speak on teacher quality. Princeton, NJ: Educational Testing Service.

Hoy, W. K., \& Woolfolk, A. E. (1990). Socialization of student teachers. American Educational Research Journal, 27, 279-300. https://doi.org/10.3102/00028312027002279

Liston, D., \& Zeichner, K. (1991). Teacher education and the social conditions of schooling. Harvard Educational Review, 61, 496-497.

National Council for Accreditation of Teacher Education. (2010). Report of the blue ribbon panel on clinical preparation and partnerships for improved student learning. Retrieved from http://www.ncate.org/LinkClick.aspx?fileticket=zzeiB1OoqPk\%3d\&tabid=715

Patan, J. (2010). Implementation of field study courses in the pre-service teacher education program in selected higher education institutions in Caraga. JPAIR Multidisciplinary Journal, 5, 11-26. https://doi.org/10.7719/jpair.v5i1.121

Pickard, M. (2004). Action research: Holding up the mirror to examine FCS teacher preparation. Journal of Family and Consumer Sciences Education, 22(2), 12-24.

Sanford, K., Hopper, T., \& Starr, L. (2015). Transforming education thinking: Complexity and relational ways of knowing complicity. An international journal of complexity and education, 12(2), 26-48. 